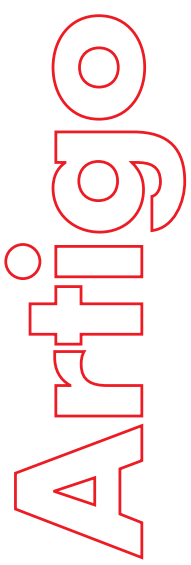

\section{Revista}

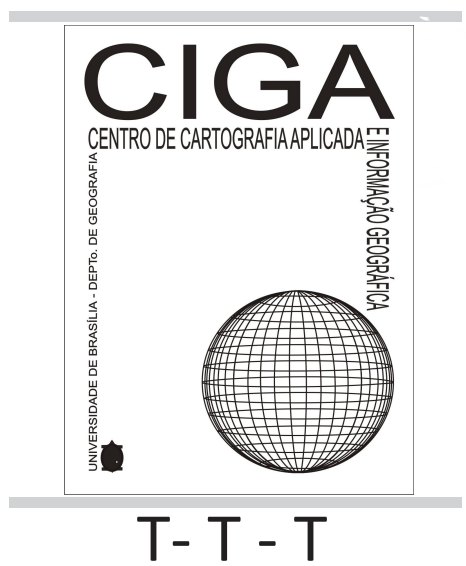

Revista Eletrônica: Tempo - Técnica - Território, V.11, N.1 (2020), 15:25 ISSN: 2177-4366

\section{AVALIACÃO dE LIVRO DIDATICO: A FALTA DE ABORDÁGENS SOBRE AS MATRIZES AFROBRASILEIRAS}

\author{
Bruno Lofrano
}

p. $15-25$

Como citar este artigo:

Lofano, B.

AVALIAÇÃO DE LIVRO DIDÁTICO: A FALTA DE ABORDÁGENS SOBRE

AS MATRIZES AFROBRASILEIRAS - Revista Eletrônica: Tempo -

Técnica - Território, v.11, n.1 (2020),p.15:25 ISSN: 2177-4366.

Disponível em: http://periodicos.unb.br/index.php/ciga/

Este obra está licenciado com uma Licença Creative Commons Atribuição - Não Comercial 4.0 Internacional. 


\title{
AVALIAÇÃO DE LIVRO DIDÁTICO: A FALTA DE ABORDÁGENS SOBRE AS MATRIZES AFROBRASILEIRAS
}

\begin{abstract}
Bruno Lofrano
Graduando em Geografia pela Universidade de Brasília, Disciplina GEOAFRO - 1 Semestre 2020. E-mail: brunolofranoporto@gmail.com
\end{abstract}

RESUMO: O presente artigo busca avaliar o livro didático "PAS - UNB 2a etapa Geografia-História” da editora exato, que é escrito em formato de apostila, com objetivo de preparar alunos de segundo ano do ensino médio para a segunda etapa do Programa de Avaliação Seriada (PAS 2) da Universidade de Brasília. Buscou-se avaliar como ou se o livro aborda conteúdos sobre as matrizes africanas e afro-brasileiras. Observou-se que o livro não aborda de forma alguma as matrizes do continente africano. Por fim, com os conhecimentos adquiridos foram feitas algumas observações sobre o livro e o que ele pode dizer sobre o sistema educacional brasileiro como um todo.

Palavras-chave: livro didático, PAS 2, matrizes africanas.

ABSTRACT: this article attempts to evaluate the textbook "PAS - UNB 2a etapa GeografiaHistória”, from the publisher Exato. The textbook is written in a specific format with the intention of preparing students for the second phase of the serial evaluation program (PAS 2) from the university of Brasilia. The focus of this composition is to evaluate how or if the textbook approaches the African and African-Brazilian matrices. It was observed that there is a complete lack of information about matrices derived from the African continent. Lastly, the knowledge gathered through this research served as a base to make some observations about the textbook and what it can mean for the Brazilian educational system as a whole.

Keywords: Textbook, PAS 2, African matrices.

\section{INTRODUÇÃO}

A Base Nacional Comum Curricular, na etapa do ensino médio, área de ciências humanas e sociais aplicadas, em sua competência específica 6, tem sua primeira habilidade descrita da seguinte forma: 
Identificar e analisar as demandas e os protagonismos políticos, sociais e culturais dos povos indígenas e das populações afrodescendentes (incluindo as quilombolas) no Brasil contemporâneo considerando a história das Américas e o contexto de exclusão e inclusão precária desses grupos na ordem social e econômica atual, promovendo ações para a redução das desigualdades étnico-raciais no país. (BRASIL, 2018, p. 581)

Essa determinada habilidade deve ser desenvolvida a longo de todos os três anos do ensino médio em todas as ciências humanas e sociais aplicadas, aqui, o foco será dado à geografia.

Visto isso, buscou-se na primeira metade do livro "PAS - UNB 2a etapa Geografia-História" (parte dedicada à geografia), da editora exato, menções sobre conteúdos relacionados às matrizes africanas e afro-brasileiras. Para isso, foram desenvolvidas uma série de perguntas a serem feitas “para o livro" com objetivo de averiguar a capacidade do livro de desenvolver tal habilidade nos estudantes. O desenvolvimento desse artigo vai seguir de forma tentar representar a "resposta” do livro para as perguntas realizadas.

\section{CONHECENDO O LIVRO}

Nome: "PAS - UNB 2ª etapa Geografia-História”

Editora: Exato

Revisão/Atualização: Eric Richardson Soares Medeiros; Assistente de revisão: Natan Ramos; Direção geral: Cássio Silva Ferreira.

Edição de 2019

O Livro é dividido em duas partes, a primeira metade é dedicada à Geografia e a segunda à história (No presente trabalho vamos nos dedicar somente à avaliação da primeira parte). A Parte sobre Geografia é dividida em 13 unidades , cada uma com múltiplos subtópicos. Sobre a forma como o conteúdo é transmitido, todas unidades são compostas por uma primeira porção explicativa, que é seguida por uma seção de exercícios, todos esses exercícios são questões tipo C (múltipla escolha), e a grande maioria das questões é retirada de edições antigas de vestibulares para universidades de todo o Brasil, bem como algumas do próprio PAS ou do ENEM, por fim, toda unidade é fechada pelo gabarito das questões disponíveis. Esse livro é parte de uma coleção de três (3), sendo um livro destinado para cada série do ensino médio. O livro em análise aqui é usado pelo segundo ano.

Figura 1. Capa do Livro

Figura 2. Sumário de Geografia 

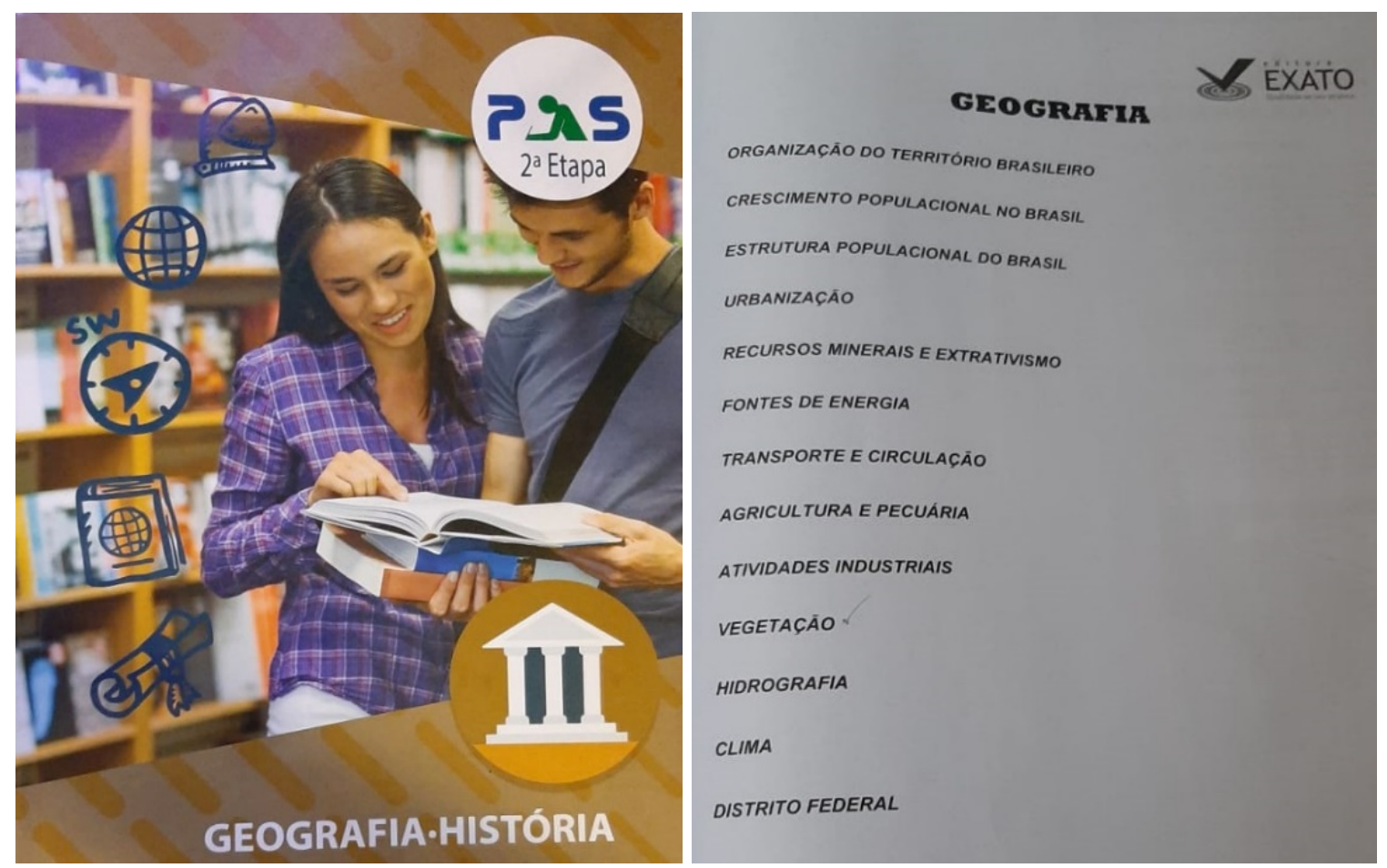

No geral o livro é bastante sintético, as explicações são muito diretas, portanto, curtas. O livro tem as páginas numeradas, mas o sumário não especifica a numeração da página de início de cada unidade.

Esse livro é parte de uma coleção, com outras apostilas que compreendem todas as outras áreas do conhecimento exigidas na prova do PAS 2, a coleção custa R\$280,00.

\section{COMO O LIVRO ENTENDE A GEOGRAFIA?}

O livro não apresenta de forma explicita em momento algum uma clarificação sobre a corrente epistemológica utilizada. Além disso, não existe uma unidade sobre “conceitos gerais da geografia”, o que dificulta bastante na identificação de uma corrente de pensamento geográfico. Em relação aos conceitos fechados que o livro apresenta, eles são praticamente todos de um caráter pouco discutível, são conceitos mais técnicos que mesmo as diferentes escolas da geografia entendem da mesma forma, são conceitos como conurbação, crescimento urbano, etc. Talvez o livro tenha mais em comum com a escola de geografia crítica, mas a relação é muito suave e abriria muito espaço para críticas. Em suma, o livro não se alinha claramente com nenhuma escola descola de pensamento geográfico.

\section{COMO O LIVRO ENTENDE O ESPAÇO GEOGRÁFICO?}

Como citado anteriormente, não há uma unidade sobre “conceitos gerais da geografia” ou apenas sobre "espaço", desta forma, não existe um conceito explícito sobre espaço geográfico no livro. O mais próximo de um conceito para espaço geográfico no livro é o tópico 1 da primeira 
unidade (Organização do Território Brasileiro), chamado de “Espaço Territorial”, como vemos na figura a seguir.

Figura 3. Conceito de Espaço Territorial da Apostila (p. 1)

\section{ESPAÇO TERRITORIAL}

Segundo os dados fornecidos pelo Instituto Brasileiro de Geografia e Estatística (IBGE), o Brasil é um país que ocupa uma área continental de $8.547 .403 \mathrm{Km}^{2}$. (censo de 2000), e um litoral com uma área de $7.376 \mathrm{Km}$, abrangendo um espaço litorôneo de $200 \mathrm{mi}$ Ihas (370 quilômetros) considerado zona econômica exclusiva. O Brasil também exerce soberania sobre o seu espaço aéreo, fiscalizando as espaçonaves que nele circulem. $O$ pais também possui soberania sobre seu subsolo, ou seja, jazidas minerais pertencem ao estado brasileiro Nesse espaço territorial a naçāo brasileira exerce seu controle soberano a partir da escolha democrática dos seus governantes, destacando-se assim como um estado pleno e verdadeiro.

Analisando o texto acima, inferimos que, no contexto desse livro, espaço é nada mais que um sinônimo para área, enquanto território seria a área administrativa de soberania. Dessa forma, o conceito de espaço é tão pobre que tenho dificuldades de chama-lo de “conceito de espaço geográfico", porque lhe falta justamente, geografia, lhe falta compreender holisticamente as dinâmicas sociais, lhe falta levar em conta a história que foi perdida e a história que permaneceu, lhe falta ser um espaço cartografavel como traz Lacoste, lhe falta ser um espaço de forças com aceleração desigual como traz Santos.

Esse livro é peculiar no sentido que ele tem um objetivo muito específico, que é ensinar os conteúdos cobreados na prova do PAS 2. Assim, seria até compreensível não dedicar uma unidade ou sequer um tópico para descrever os conceitos básicos da geografia. Porém, deveria ser possível fazer a inferência desse conceito a partir do resto livro, um conceito geográfico, mas adotar espaço como sinônimo de área é consideravelmente empobrecedor até mesmo para esse tipo de livro didático.

\section{COMO O LIVRO ABORDA AS QUESTÕES ÉTNICO-RACIAIS?}

Não existe nenhuma unidade ou tópico dedicado a abordar as questões étnico-raciais no Brasil, na verdade vemos uma escassez completa de informações sobre etnia. Novamente, dado o objetivo do livro e entendendo a negação geral do sistema quanto às questões étnico-raciais era, de certa forma, até esperado que o livro não reservaria uma porção significativa para esse conteúdo, não que isso seja correto ou positivo para o contexto social e educacional. 
O que é realmente surpreendente é a completa negação das dinâmicas étnico-raciais, e sociais no geral. Espera-se que um livro que se dedica tanto para a análise demográfica, entregando duas unidades inteiras e alguns tópicos da última unidade "Distrito Federal” para esse estudo, reconheça a importância que as diferentes cores e etnias têm na construção de um povo. Vemos sinais dessa negação, ou ignorância, na introdução da terceira unidade, coo é possível observar na figura abaixo.

Figura 4. Tópico 1 da Unidade Sobre Estrutura Populacional do Brasil (p. 13)

\section{CARACTERÍSTICAS GERAIS}

Para se entender a estrutura populacional de um país, devese analisar como a populaçāo está distribuída pelo território, de acordo com critérios como a idade, o sexo, as atividades econômicas e seus rendimentos.

O Livro considera todos os critérios menos a questão racial. É quase inadmissível ignorar essa questão, especialmente em um país africano como Brasil, um país onde a maior parte da população é de pretos ou pardos. Na unidade sobre DF isso é novamente evidente. A unidade levanta tópicos sobre: "aspectos políticos” sem falar de representatividade ou preconceito; “Crescimento urbano" sem falar de exclusão ou periferização; “Questão da terra no DF” sem falar sobre os terreiros religiosos que não possuem posse legal de sua terra.

Outra unidade na qual as questões étnico-raciais poderiam ter sido abordadas é a unidade sobre Urbanização. Mas não existe citação alguma sobre isso nessa quarta unidade. Até existem menções a favelas e hierarquia de cidades, mas não existe nada sobre exclusão espacial e marginalização da população afro-brasileira. A imagem a seguir mostra uma parte da unidade de urbanização, quando o texto fala sobre as consequências sociais da urbanização. É uma das poucas menções sobre problemas ou questões sociais no livro, mas ainda peca na abordagem étnico-racial.

Figura 5. Recorte de Texto da Unidade "Urbanização" (p. 19)

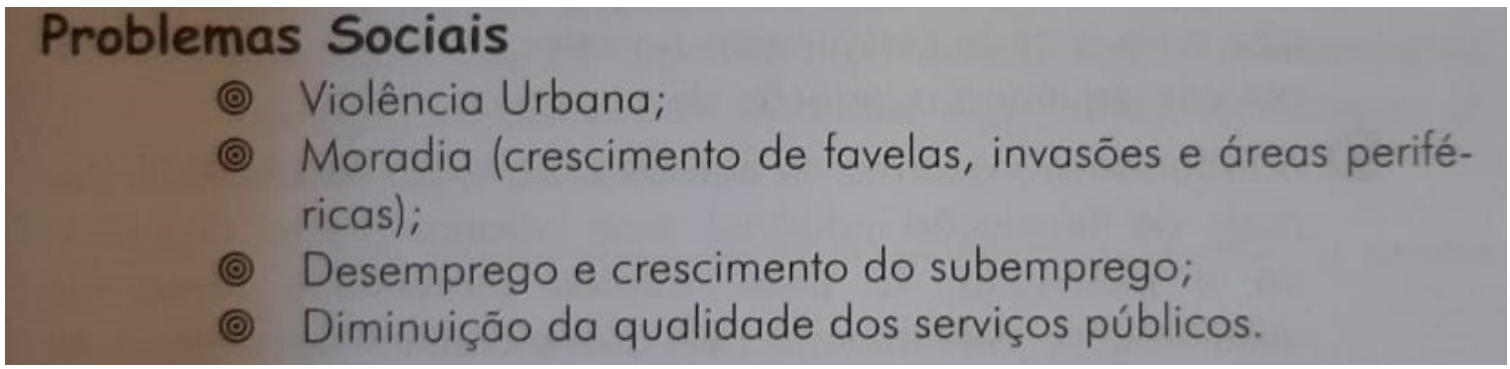




\section{O LIVRO APRESENTA EXPLICAÇÕES SOBRE O SISTEMA}

\section{ESCRAVISTA?}

O livro não apresenta explicações sobre o sistema escravista do Brasil. Não existe nenhuma unidade dedicada a esse conteúdo, mas existem alguns outros pontos que têm relação direta com o sistema escravista, portanto deveria haver uma explicação sobre o mesmo, mas, como é tendência no livro, essa questão é ignorada.

Figura 6. Tópico de Texto (p. 17)

\section{Século XVI}

As primeiras cidades brasileiras surgiram ao longo do litoral, pelo fluxo comercial da produção do açúcar que iria abastecer a metrópole. Embora a produçāo de cana-de-açúcar se realizasse no cam. po, a sua comercializaçâo levou ao desenvolvimento de uma atividade urbana. Grande parcela dessas cidades se tornaram centros comerciais e politico-administrativos, como no caso de Salvador. A lavoura canavieira permitiu apenas um pequeno crescimento urbano, fato marcante no Brasil por cerca de dois séculos. No Brasil, existiam poucas cidades localizadas no litoral, que tinham como base econômica as exportaçōes, no sentido de que, o mercado interno era altamente deficiente, pois uma grande parcela da populaçáo (escravos) nâo possuía renda para consumir.

\section{Século XVIII}

Com a descoberto de ouro na regiāo central do Brasil, houve a mudança do eixo econômico do litoral para o interior, o que fez surgir uma quantidade significativa de pequenas e médias cidades. Embora a mineraçāo tenha propiciado um crescimento urbano considerável, várias das cidades formadas entraram em crise com a estagnaçāo da atividade nas minas. Esse fator fez com que no Brasil nessa época nāo fosse desenvolvida uma quantidade ampla de cidades de médio porte.

Figura 7. Tópico de Texto (p. 47)

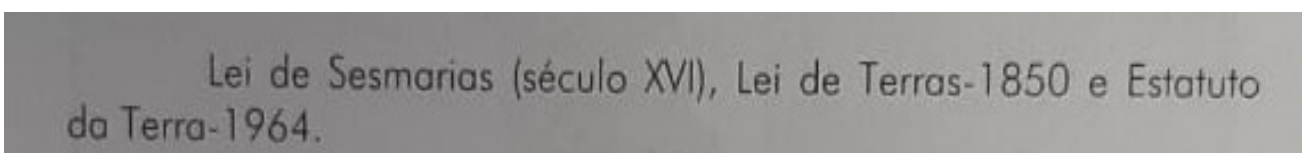

As imagens acima são da unidade sobre urbanização e agricultura e pecuária, respectivamente. Essas são unidades nas quais o sistema escravista poderia e deveria ser mencionado. Contudo, o texto explicativo comenta diversos aspectos que tem relação direta com o Estado escravocrata, como as economias açucareira e mineradora e as leis de sesmarias e de terras, mas opta por não esclarecer o mesmo. 
Posteriormente, o livro menciona também o ciclo do café e a industrialização, mas não chega a comentar a abolição da escravatura. Também existe margem para comentar a libertação e subsequente deportação dos escravos na unidade "Urbanização”, mas isso não é feito.

\section{O LIVRO APRESENTA IMAGENS ESTEREOTIPADAS DE PESSOAS OU} CONTEXTOS AFRO-BRASILEIROS?

O Livro não apresenta nenhum tipo de figura estereotipada de pessoas ou culturas afrobrasileiras, da mesma forma que o livro não apresenta nenhuma figura de pessoas ou contextos afrobrasileiros. As imagens do livro são, em sua grande maioria mapas, vemos também alguns esquemas explicativos em forma de imagem, existem pouquíssimas fotografias no livro, quase todas de paisagens agrícolas. Todos os mapas e esquemas são usados para representar visualmente algum conteúdo textual que acaba de ser explicado. Como não temos nenhum conteúdo sobre matrizes ou contextos afro-brasileiros, não existe nenhuma imagem que explique esses contextos. Essa falta de imagens mostra uma falta de compromisso do livro com a realidade atual, com a representatividade.

Existe no livro, na parte de exercícios, uma questão retirada de alguma edição anterior do

PAS uma imagem, que mostra pessoas pretas em uma manifestação. Não vejo estereotipagem nenhuma na foto, mas dado que é única foto do livro com alguma representatividade afro-brasileira, é valido trazer para este ensaio.

Figura 8. Questão da Unidade “Agricultura e Pecuária” (p. 53)

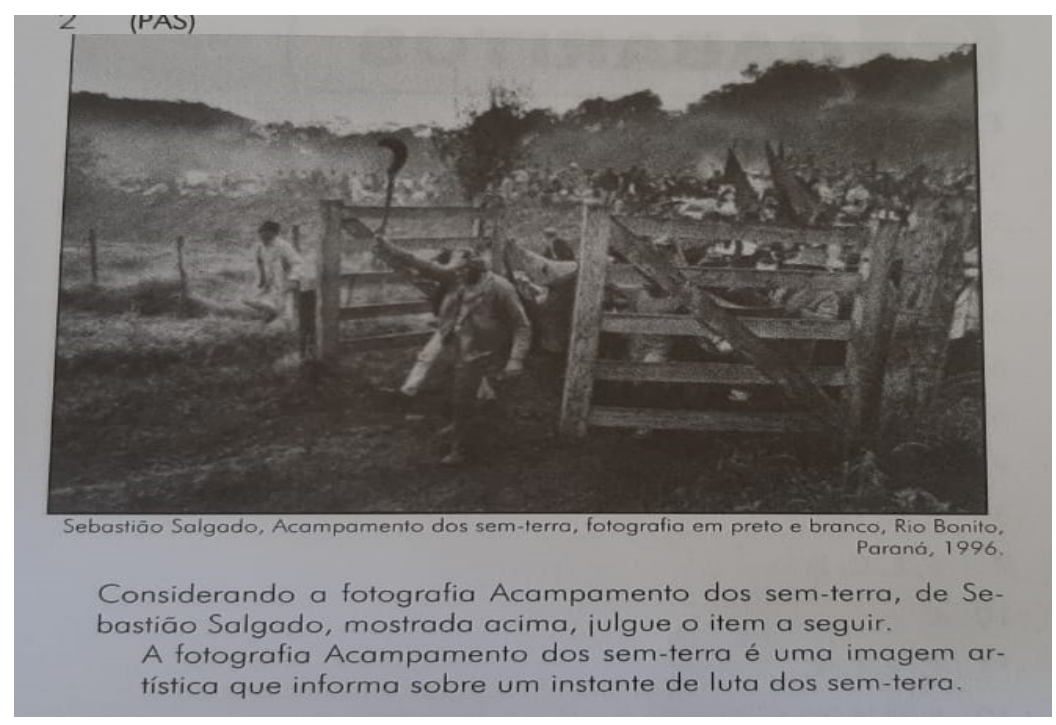

O LIVRO APRESENTA ALGUMA REFERÊNCIA SOBRE A DIVISÃO DA SOCIEDDADE BRASILEIRA EM GRUPOS ETNICOS OU SOBRE A SITUAÇÃOA ATUAL DOS AFRO-BRASILEIROS? 
Como já foi citado repetidas vezes, o livro ignora as populações afro-brasileiras em suas caracterizações demográficas e territoriais. Além disso, o livro não apresenta mapas de distribuição populacional, o mais próximo disso que o livro chega a apresentar é um mapa da distribuição regional, com alguns esquemas que comentam a população relativa de cada região, mas não fala nada sobre etnias.

Figura 9. Mapa da Divisão Regional do Brasil (p. 4)

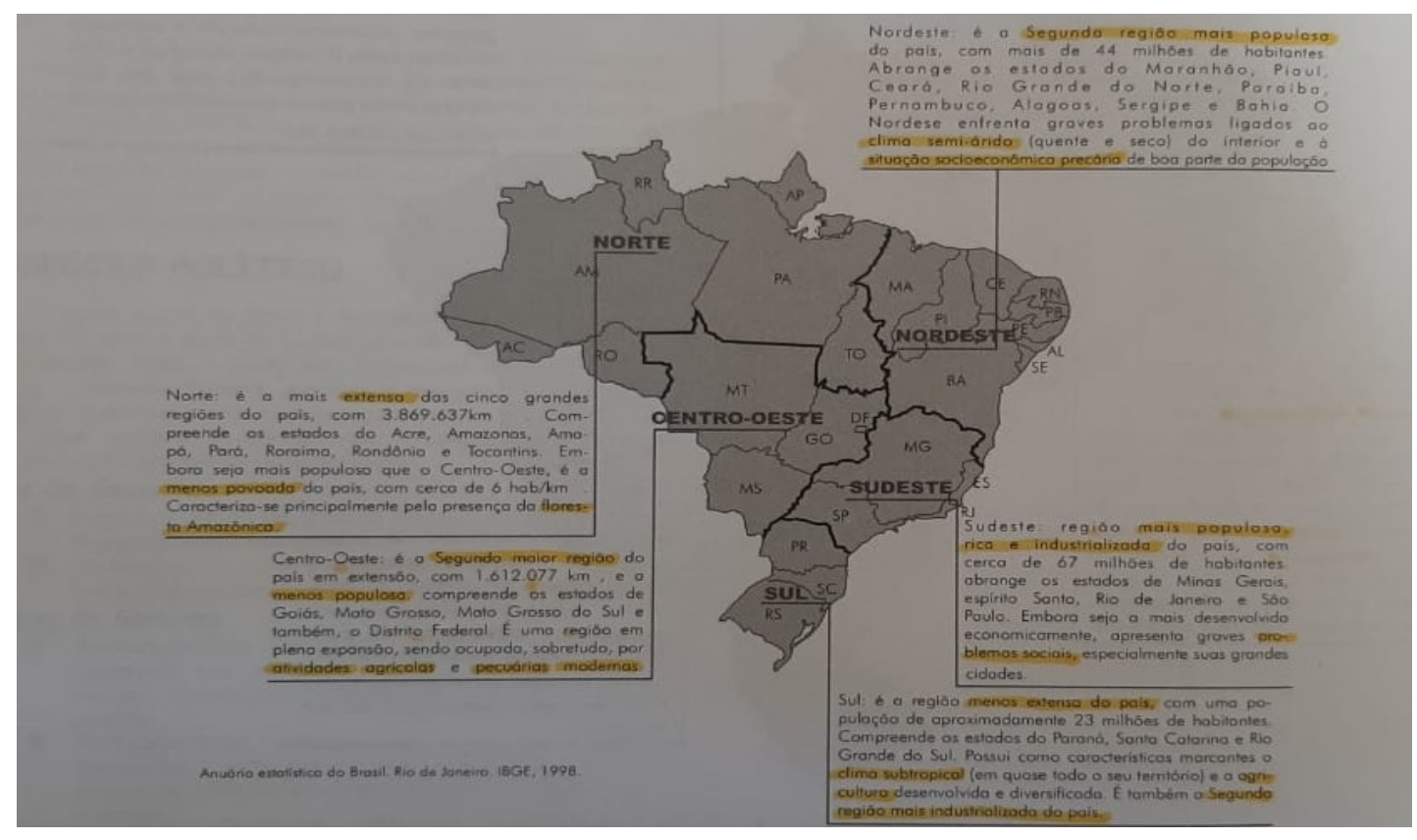

Além disso, o livro faz divisões na população e traz tabelas que apresentam esses resultados, mas essas divisões demográficas são apenas em termos de sexo e faixa etária.

Tabela 1. Distribuição da População por Sexo Biológico (p. 9)

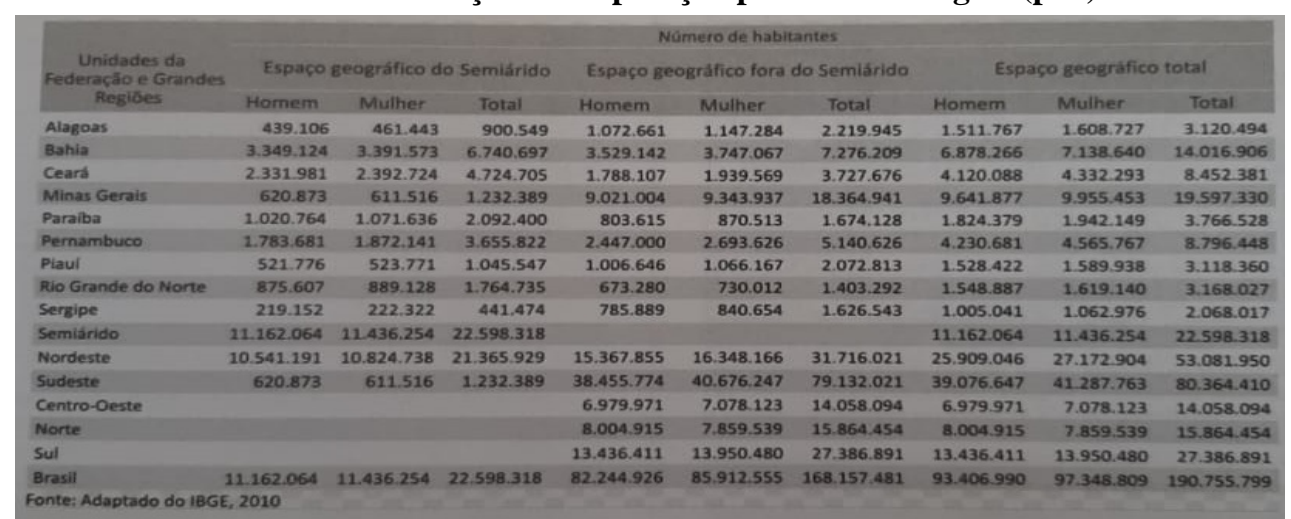

Quanto à uma possível abordagem sobre a situação atual dos afro-brasileiros, o livro não apresenta nenhuma referência quanto à essa realidade. Na verdade, o livro não apresenta nenhuma referência muito atual, a grande maioria das estatísticas é de antes de 2015, os mapas apresentam contextos antigos ou atemporais e a maioria dos processos estudados só é analisada no plano passado. 
Existem diversas instâncias no livro onde a situação dos afro-brasileiros podia ter sido apresentada, e se fosse, seria uma excelente adição e complementação ao conteúdo, seguem alguns exemplos:

A primeira unidade “Organização do Território”: Esse é um conteúdo de abrangência quase infinita. O livro apresenta apenas as organizações oficiais, do IBGE, mas existem múltiplas lentes para analisarmos a organização do território. Uma excelente forma de análise aqui é a organização fazer a relação histórica (já que o livro tanto gosta de falar do passado) das áreas ocupadas na época da colonização e hoje, e correlacionando isso com o local onde as populações afro-brasileiras estão sendo forçadas a viver, expulsas do campo, que é historicamente africano no Brasil.

“Estrutura populacional do Brasil”: É inimaginável falar de estrutura populacional, e não mencionar a questão racial. Todos fatores estruturais apresentados são importantes, como também é a população afro-brasileira, que é maioria. Além disso, falando de estrutura populacional, existe hoje a necessidade de discutir o racismo estrutural, esse sistema de dominação que, provavelmente, teve influência nos autores do livro quando eles optaram por omitir um conteúdo tão denso e tão importante, como é a geografia africana, na produção desse livro.

“Urbanização”: É quase consenso nos grandes autores da geografia, como Milton Santos e David Harvey, que o processo de urbanização foi muito desigual e gerou muitas desigualdades espaciais e territoriais. É notório também o processo de exclusão e marginalização que ocorreu com a população afro-brasileira especialmente nas grandes cidades, mas o livro não comenta nada disso.

Esses são apenas alguns exemplos de possíveis formas que o livro poderia e deveria ter incluído a situação de populações afro-brasileiras na atualidade dentro do seu conteúdo.

\section{O LIVRO APRESENTA ALGUMA EXPLICAÇÃO SOBRE A POSIÇÃO DESIGUAL DOS DESCENDENTES AFRICANOS NO TRABALHO, SAÚDE, EMPREGO OU EDUCAÇÃO.}

Não existe explicação nenhuma para essa questão no livro, já que o mesmo optou por omitir toda essa realidade, desde suas origens na escravidão, até o período atual com o racismo estrutural.

Na verdade, esse livro não trata muito bem de nenhum desses quatro conteúdos, Trabalho, Saúde, Emprego e Educação. O trabalho é sim mencionado, no contexto da industrialização, agricultura e pecuária e fontes de energia, mas com uma escassez de estatísticas sobre emprego e desemprego da população, representatividade dos grupos étnicos nas questões trabalhistas, etc. Então apesar de estarem relacionados o trabalho e o emprego são representados heterogeneamente no livro. Quanto à saúde, o livro chega a mencionar, falando um pouco de taxas de natalidade e mortalidade 
na unidade sobre “Crescimento Populacional no Brasil”, mas não passa disso. Já a educação, ou escolaridade são basicamente ignoradas no livro todo. Em suma, o livro que já não comenta nada sobre os afro-brasileiros não consegue contemplar o porquê dessa posição desfavorável.

\section{AVALIAÇÃO FINAL}

O Livro não considera a matriz africana como verdadeira referência da formação da sociedade brasileira, não só isso, o livro basicamente não fala da formação espacial da sociedade brasileira, muito menos da influência dos povos africanos ou tradicionais.

Toda a análise feita até o momento culmina em vários questionamentos na real capacidade que esse livro tem de formar um aluno crítico. Porém, ele continua sendo vendido e recebendo novas atualizações anualmente. Isso se dá porque, apesar dos problemas que ele apresenta, ele cumpre seu objetivo. Objetivo esse de preparar candidatos para a prova do PAS 2 na área de Geografia. É difícil argumentar o contrário, de fato, as explicações do livro são diretas e claras, as questões promovem boa prática para o modelo de exercícios encontrado na prova e os conteúdos expostos condizem com a matriz do PAS.

A realidade, por mais desmoralizante que seja, é essa, e revela muito sobre o sistema educacional brasileiro atual. Esse livro é utilizado porque, apesar de ruim no contexto holístico da ciência geográfica, cumpre o seu objetivo muito bem. Qualquer geógrafo identifica com facilidade as deficiências conteudísticas desse livro, mas a ambição desse livro nunca foi de ser um exemplar livro didático de geografia para todos os públicos, foi de apenas de ensinar os consumidores dele a fazerem uma prova específica.

Tendo em mente o contexto exposto acima, faz bastante sentido ele ser material de estudo para candidatos do PAS 2. Mas é importante entender que não é todo candidato que terá acesso a esse preparo extra-escolar. Quem consegue e se dispõe a comprar apostilas como essa é, no geral, o estudante de escolas da rede privada, que são sem dúvida excludentes e elitistas, meramente por conta do preço da mensalidade (ainda que muitas ofereçam provas para bolsas de estudos). Ou seja, o aluno que pode comprar um livro como esse é o aluno que já tem uma certa vantagem na competição por uma vaga na universidade, e sabe-se que, no geral, as escolas privadas têm muito mais alunos brancos do que pretos, pardos ou indígenas, então muitas vezes, a falta de conteúdos sobre as matrizes africanas passa despercebida.

Existem muitos conteúdos que podem ser indicados que o livro deveria apresentar, as matrizes africanas obviamente são um exemplo, mas, ao longo desse trabalho, essa crítica já foi feita diversas 
vezes, talvez, agora, ela possa ser um pouco mais ampla, a crítica nesse momento vai ser sobre a comercialização da educação e aos sistemas avaliativos vestibulares.

Primeiramente, sobre os vestibulares, apesar de a legislação vigente hoje no Brasil tornar o ensino sobre o conteúdo relacionado ao continente africano obrigatório, esse conteúdo não faz parte da maioria dos vestibulares, no contexto do Distrito Federal, o principal vestibular, o PAS, não cobra esse conteúdo, pelo menos não na segunda etapa. Paralelamente a isso, os livros e apostilas que têm como principal objetivo ensinar os alunos a dominarem essas provas, pecam no ensino do conteúdo sobre as matrizes africanas. Esses dois fatores não têm necessariamente uma relação de causa e efeito, mas existe, no mínimo uma correlação.

\section{CONCLUSÃO}

Em suma, o ensino sobre as matrizes africanas é crucial para a formação de um aluno capaz de criticar e combater o sistema racista secular encontrado no Brasil. O ato de não ensinar esses conteúdos e a tendência de empobrecimento geral da educação citado acima contribui, talvez não conscientemente, para a manutenção do Estado racista. A mudança necessária não é de fácil execução, mas um bom ponto de início é a melhora geral dos livros didáticos e nas formas de avaliação.

\section{REFERÊNCIAS BIBLIOGRÁFICAS}

BRASIL. Ministério da Educação. Base Nacional Comum Curricular. Brasília, 2018

EDITORA EXATO. PAS segunda etapa geografia-história. Edição de 2019. Brasília. 2019.

LACOSTE, Y. A geogrfia - isso serve, em primeiro lugar para fazer a guerra. Tradução Maria Cecília França. Campinas: Papirus. 1988, 133 p.

SANTOS, M. Por uma Geografia Nova. São Paulo: Hucitec, Edusp, 1978. 